\title{
Quality characteristics of parental lines of wheat mapping populations
}

\author{
Antonella Pasqualone ${ }^{1}$, Luciana Piarulli², Giacomo Mangini², \\ Agata Gadaleta², Antonio Blanco ${ }^{2}$ and Rosanna Simeone ${ }^{2}$ \\ ${ }^{1}$ Food Science and Technology Unit, University of Bari, Department of Soil, Plant and Food Sciences, Via Amendola, 165/A, I \\ 70126, Bari, Italy \\ ${ }^{2}$ Genetics and Plant Breeding Unit, University of Bari, Department of Soil, Plant and Food Sciences, Via Amendola, 165/A, I \\ 70126, Bari, Italy \\ email: antonella.pasqualone@uniba.it
}

\begin{abstract}
The aim of this work was to evaluate the main quality traits in the parental lines of wheat segregating populations to identify the best for subsequent genetic mapping of the traits. Significant differences $(p<0.001)$ among wheat genotypes were observed. Many of the examined crosses appeared to be suitable for the purpose, showing differences among parental lines as high as $4.6 \%$ for protein content, $6.4 \%$ for gluten content, 69 for gluten index, $50 \mathrm{~mL}$ for sodium dodecyl sulphate sedimentation volume, and $33.9 \mathrm{~g}$ for thousand-kernel weight, whereas differences accounting for 4.8, 2.4, and 7.3 were observed for yellow index, red index and brown index, respectively. The results pointed out that for studying at the same time the quantitative and qualitative features of gluten, the wheat populations derived from Latino x MG29896 and Saragolla x 02-5B-318 could be particularly appropriate. In addition, the latter cross was suitable to deepen the knowledge of yellow index regulation.
\end{abstract}

Key words: wheat, whole meal, mapping population, protein, gluten

\section{Introduction}

The most important quality characteristics for both bread and pasta are the textural and color features. The first, both in soft and durum wheat, are strongly related to the quali-quantitative characteristics of gluten-forming proteins, which properties allow wheat flour to be transformed into bread or pasta (Goesaert et al. 2005). Moreover, when high-temperature drying technology is used, protein content remains the most important parameter influencing the cooking quality of pasta ( $D^{\prime}$ Egidio et al. 1990).

Color influences consumer choice at the moment of purchase: bright yellow pasta, arising from carotenoid pigments of durum wheat semolina (Feillet et al. 2000) is preferred over pale or discolored products. In addition, carotenoids increase the nutritional value (Garcia-Casal 2006). Similarly, when semolina is used in bread-making, as usually made in Southern Italy (Pasqualone 2012) and in Mediterranean countries (Qaroni 1996), its pigments confer a distinctive and appreciated yellowish tone to bread crumb (Pasqualone et al. 2004, 2007). Undesired color alterations, mainly browning, can derive from Maillard's reaction or enzymatic activity. Polyphenol oxidase, in particular, abundant in the varieties richer of phenolics (Pasqualone et al. 2014), is correlated with both dough darkening (Taranto et al. 2012) and color alterations of noodles (Fuerst et al. 2006) and bread (McCallum and Walker 1990). On the other hand, pigmented wheats - red, purple, or blue - are becoming the object of interest due to their high anthocyanin content (Ficco et al. 2014).

Many breeding efforts have been devoted to increase the quality features of wheat. In particular, genetic linkage maps, that locate genes related to traits of interest, are an useful tool in breeding programs. The availability of markers linked to quantitative trait loci (QTLs) facilitates the genetic dissection of quantitative traits and the early selection in wheat breeding programs. Detecting QTLs by molecular markers involves the analysis of populations constituted by large number of individuals which segregate concurrently for marker loci and quantitative trait expression. Double haploid and recombinant inbred populations are particularly suited for this purpose as they can be characterized for additional loci at any time and analyzed in combination with the previously accumulated data, assumed that parental lines are sufficiently differentiated for the traits of interest, so as to ensure segregation. Such lines constitute permanent mapping populations that may be evaluated over space and time (Mather and Jinks 1971). 
Previous papers have reported the effective detection and mapping of quantitative trait loci (QTLs) related to protein content (Blanco et al. 2002), sodium dodecyl sulphate sedimentation volume (Blanco et al. 1998), yellow pigments (Blanco et al. 2011) and yield components (Blanco et al. 2001) in recombinant inbred populations of tetraploid wheat. However, some genes are cultivar specific, hence it is needed to investigate on them in several mapping populations (Bernardo 2008).

The aim of this work was to evaluate the main quality traits (thousand-kernel weight, protein content and composition, quali-quantitative features of gluten, color indices) of parental lines of existing wheat mapping populations to identify the best to be used for subsequent mapping of the traits of interest in the derived segregating progeny.

\section{Material and methods}

\section{Samples}

Twenty-nine wheat accessions and cultivars, reported in Table 1,were considered. All of them were parental lines of segregating populations set up at the Genetics and Plant Breeding Unit, Department of Soil, Plant and Food Sciences (DISSPA), University of Bari (Italy), for a total of 28 crosses, as specified in Table 2. The plants were grown in the experimental field of the Department of Soil, Plant and Food Sciences at Valenzano (Bari, Italy) in 2013, in a randomized complete block design with three field replicates and plots consisting of 1-m rows, $30 \mathrm{~cm}$ apart, with 50 germinating seeds per plot. During the growing season, $120 \mathrm{~kg} \mathrm{ha}^{-1} \mathrm{~N}$ were applied and standard cultivation practices were adopted. Plots were hand-harvested at maturity. A seed sample $(15 \mathrm{~g})$ per plot was used to determine the thousand-kernel weight (KW).

\section{Basic chemical and physical determinations}

Harvested grain samples from each plot were separately milled to whole meal on a laboratory mill equipped with 1-mm sieve (Cyclotec Sample Mill, Tecator Foss, Hillerød, Denmark). Moisture content was determined at $105^{\circ} \mathrm{C}$ by means of an automatic moisture analyzer (Radwag Wagi Elektroniczne, Radom, Poland). Grain protein content (GPC) was determined by using a dual beam near infrared reflectance spectrophotometer (Zeutec Spectra Alyzer Premium, Zeutec Büchi, Rendsburg, Germany). Colorimetric evaluations of yellow index (YI, corresponding to $\left.b^{*}\right)$, red index $\left(\mathrm{RI}, a^{*}\right)$, and brown index $\left(\mathrm{BI}\right.$, defined as $\left.100-L^{*}\right)$, were carried out by means of the reflectance colorimeter Chroma Meter CR-300 (Konica Minolta Sensing, Osaka, Japan). Whole meal was placed into the granular materials attachment CR-A50 (Konica Minolta Sensing, Osaka, Japan) of the colorimeter to obtain a smooth surface suitable for color readings. Results were the average of two analytical replications apart for colorimetric evaluations that were replicated 5 times.

Table 1. Taxonomic classification of the wheat cultivars and accessions considered

\begin{tabular}{|c|c|}
\hline Taxonomic classification & Type of plant material \\
\hline \multicolumn{2}{|l|}{ Triticum aestivum L. ssp. aestivum } \\
\hline Chinese Spring & Cultivar \\
\hline Chinese Spring - 5A dic. & $\begin{array}{l}\text { Chinese Spring disomic substitution line of 5A chromosome } \\
\text { with the accession TA106 of ssp. dicoccoides }\end{array}$ \\
\hline 02-5B-318 & Breeding line \\
\hline \multicolumn{2}{|l|}{ Triticum turgidum ssp. dicoccum (Schrank ex Schübler) Thell. } \\
\hline MG5323 & Landrace \\
\hline \multicolumn{2}{|l|}{ Triticum turgidum ssp. dicoccoides (Körn. ex Asch. \& Graebner) Thell. } \\
\hline MG4343; MG4330; MG29896 & Wild accessions \\
\hline \multicolumn{2}{|l|}{ Triticum turgidum ssp. durum (Desf.) Husnot } \\
\hline Cltr 14629 & Purple line derived from an Ethiopic landrace \\
\hline UC1113 & $\begin{array}{l}\text { UC Davis breeding line with the high grain protein content } \\
\text { gene GpcB1 }\end{array}$ \\
\hline $\begin{array}{l}\text { Anco Marzio; Aureo; AC Avonlea; Ciccio; Duilio; Fiore; Grecale; Iride; } \\
\text { Isildur; Latino; Latinur; Liberdur; Messapia; Neolatino; Normanno; Preco; } \\
\text { Primadur; Saragolla; Svevo; Tiziana }\end{array}$ & Cultivars \\
\hline
\end{tabular}




\section{Determination of quali-quantitative features of gluten}

Wet gluten (WG) and gluten index (GI) were determined according to the ICC Standard No. 155 (ICC 1994) by means of the complete system consisting of Glutomatic 2200, Centrifuge 2015, and Glutork 2020 (Perten Instruments $A B$, Huddinge, Sweden). First, WG was recovered by means of Glutomatic 2200 (Perten Instruments $A B$, Huddinge, Sweden). Then, GI was calculated as the percent ratio of the WG fraction remaining on the sieve after centrifugation (Centrifuge 2015, Perten Instruments AB, Huddinge, Sweden) to the total WG weight. Dry gluten (DG) was determined by drying the total WG at $150^{\circ} \mathrm{C}$ for 4 min by means of Glutork 2020 apparatus (Perten Instruments $\mathrm{OAB}$, Huddinge, Sweden). Gluten hydration index (GHI) was calculated as the percent ratio (WG - DG)/ WG. Results were the average of two analytical replications.

\section{Sedimentation volume in sodium dodecyl sulphate (SDS-SV)}

The test of SDS-SV was performed according to the ICC Standard method no. 151 (ICC 1990). Results were the average of two analytical replications.

\begin{tabular}{llll}
$\begin{array}{l}\text { Table 2. Pairs of parental lines and progeny size of } 28 \text { wheat mapping populations set up at the Genetics and } \\
\text { Plant Breeding Unit, Department of Soil, Plant and Food Sciences, University of Bari, Italy }\end{array}$ \\
\hline Cross & $\begin{array}{l}\text { Progeny } \\
\text { individuals (no.) }\end{array}$ & Cross & $\begin{array}{l}\text { Progeny } \\
\text { individuals (no.) }\end{array}$ \\
\hline Aureo x Normanno & 896 & Iride x Fiore & 180 \\
Aureo x Iride & 616 & Svevo x MG4330 & 177 \\
Saragolla x 02-5B-318 & 421 & Grecale x Tiziana & 160 \\
Neolatino x Preco & 409 & Iride x Ciccio & 160 \\
Latinur x Saragolla & 405 & Normanno x Fiore & 160 \\
Isildur x Saragolla & 405 & Duilio x AC Avonlea & 150 \\
Liberdur x Saragolla & 324 & Cltr 14629 x Grecale & 148 \\
Svevo x Primadur & 322 & Latino x MG29896 & 144 \\
UC1113 x Iride & 320 & Grecale x Fiore & 130 \\
Isildur x Anco Marzio & 308 & Latino x MG5323 & 122 \\
Liberdur x Anco Marzio & 296 & Messapia x MG4343 & 122 \\
Normanno x Tiziana & 260 & Latino x Primadur $^{\mathrm{d}}$ & 121 \\
Svevo x Messapia & 249 & Svevo x Ciccio & 120 \\
Chinese Spring x Chinese Spring - 5A dic. ${ }^{\text {a }}$ & 188 & Iride x Tiziana & 90
\end{tabular}

a ${ }^{\mathrm{G}}$ adaleta et al. 2012, 2014; ${ }^{\mathrm{b} P i a r u l l i}$ et al. 2012; 'Blanco et al. 1998, 2001, 2002; 'Blanco et al. 2011; 'Blanco et al. 2012.

\section{Electrophoretic analyses of seed storage proteins}

Gliadins and glutenins were extracted from $60 \mathrm{mg}$ whole meal flour and analyzed by polyacrylamide gel electrophoresis in acidic conditions (A-PAGE) and sodium dodecyl sulphate polyacrylamide gel electrophoresis (SDS-PAGE), respectively, on a Protean II apparatus (Bio-Rad, Hercules, CA), according to the conditions of Lukow et al. (1990).

\section{Statistical analyses}

Standard ANOVA (with genotype as fixed factor and replication as random factor) was performed using the software MSTAT-C (Michigan State University, East Lansing, MI). The differences $(\Delta)$ between pairs of parental lines of segregating populations were calculated and the Fisher's least significant difference at $5 \%$ significance level $\left(\mathrm{LSD}_{0.05}\right)$ was applied to point out the most polymorphic pairs for the traits analyzed. Pearson phenotypic correlation coefficients $(R)$ were calculated among all traits.

\section{Results and discussion}

\section{Variability of quality characteristics and correlations among them}

Glutenins and gliadins encoded at the Glu-1 and Gli-1 loci are the most commonly considered in wheat breeding programs aimed to improve gluten quality. The glutenin composition, in particular, has been used to establish a quality score, as extensively reviewed by Shewry et al. (1992). The allelic variations of high molecular weight glutenin sub- 
A. Pasqualone et al. (2015) 24: 118-127

units (HMW-GS) and of $\omega$ - and $\gamma$-gliadins in the wheat cultivars and accessions considered are reported in Table 3 . Three different HMW-GS alleles at the Glu-A1 locus, 5 HMW-GS alleles at the Glu-B1 locus, and 5 different gliadin alleles at the Gli-B1 locus, were observed. The number of alleles at each loci decreased to 2 if durum wheat cultivars only were considered. Due to the breeding process, the majority of cultivars contained HMW-GS 7+8 subunits, that are characterized by a higher quality score than $6+8$ or 20 subunits (Boggini and Pogna 1989, Shewry et al. 1992). The Triticum aestivum cultivar Chinese Spring and its disomic substitution line showed a 2+12 pattern at the Gli-D1 locus, known to be related to lower gluten quality if compared to the $5+10$ combination. Latino was the only cultivar characterized by $\mathrm{Y}-42$ gliadin. With few exceptions (Pogna et al. 1990), this gliadin is associated to type-1 low molecular weight glutenin subunits (LMW-GS 1), related to low technological quality (Boggini and Pogna 1989). The $\gamma-45$ gliadin, usually related to type-2 LMW-GS and considered an easily detectable quality marker (Boggini and Pogna 1989), was observed in the improved Neolatino cultivar (derived from Latino) and in all the other cultivars. In addition, Neolatino showed also the HMW-GS 2* subunit, that positively influences quality more than the null allele that, instead, characterized all the other cultivars. As expected, the landrace MG5323 and the wild accessions MG4343, MG4330, and MG29896 showed the most differentiated patterns in terms of both gliadins and HMW-GS.

The analysis of variance carried out on GPC, quali-quantitative characteristics of gluten, SDS-SW, KW, and color indices of parental lines of wheat mapping populations revealed highly significant differences $(p<0.001)$ among genotypes for all the traits (Table 4).

Table 3. Allelic composition of high molecular weight glutenin subunits (HMW-GS) and of $\omega$ - and $\gamma$-gliadins, encoded at Glu-A1, Glu-B1, and Gli-B1 loci, detected in wheat cultivars and accessions

\begin{tabular}{|c|c|c|c|c|c|c|}
\hline \multirow{3}{*}{ Parental line } & \multicolumn{6}{|l|}{ Locus } \\
\hline & \multicolumn{2}{|l|}{ Glu-A1 } & \multicolumn{2}{|l|}{ Glu-B1 } & \multicolumn{2}{|l|}{ Gli-B1 } \\
\hline & $\begin{array}{l}\text { HMW-GS } \\
\text { subunit } \\
\text { composition }\end{array}$ & $\begin{array}{l}\text { Allele } \\
\text { code }\end{array}$ & $\begin{array}{l}\text { HMW- } \\
\text { GS subunit } \\
\text { composition }\end{array}$ & $\begin{array}{l}\text { Allele } \\
\text { code }\end{array}$ & Gliadin composition & $\begin{array}{l}\text { Allele } \\
\text { code }\end{array}$ \\
\hline Chinese Springa & null & $\mathrm{C}$ & $7+8$ & $\mathrm{~b}$ & $\omega-31-35-38, \gamma-42$ & \\
\hline Chinese Spring - 5A dic. ${ }^{a}$ & null & C & $7+8$ & $b$ & $\omega-31-35-38, \gamma-42$ & \\
\hline $02-5 B-318$ & n.d. & & n.d. & & n.d. & \\
\hline MG5323 & 1 & a & 22 & $\mathrm{k}$ & $\omega-31-33, \gamma-45$ & \\
\hline MG4343 & 1 & $\mathrm{a}$ & $18+23$ & & $\omega-31-33, \gamma-45$ & \\
\hline MG4330 & $2 *$ & $b$ & 20 & $\mathrm{e}$ & $\omega-31-35-38, \gamma-45$ & \\
\hline MG29896 & 1 & $\mathrm{a}$ & $6+8$ & $d$ & $\omega-31, \gamma-45$ & \\
\hline Cltr 14629 & n.d. & & n.d. & & n.d. & \\
\hline UC1113 & null & $\mathrm{C}$ & $7+8$ & $b$ & $\omega-35, \gamma-45$ & c \\
\hline Anco Marzio & null & $\mathrm{C}$ & $7+8$ & $b$ & $\omega-35, \gamma-45$ & c \\
\hline Aureo & n.d. & & $6+8$ & & $\omega-35, \gamma-45$ & \\
\hline AC Avonlea & n.d. & & n.d. & & $\omega-35, \gamma-45$ & \\
\hline Ciccio & null & C & $7+8$ & $b$ & $\omega-35, \nu-45$ & c \\
\hline Duilio & null & c & $7+8$ & $b$ & $\omega-35, \gamma-45$ & c \\
\hline Fiore & null & C & $7+8$ & $b$ & $\omega-35, \gamma-45$ & c \\
\hline Grecale & null & $\mathrm{C}$ & $6+8$ & $d$ & $\omega-35, \gamma-45$ & C \\
\hline Iride & null & C & $7+8$ & $b$ & $\omega-35, \gamma-45$ & C \\
\hline Isildur & n.d. & & n.d. & & n.d. & \\
\hline Latino & null & C & $7+8$ & $b$ & $\omega-33-35-38, v-42$ & a \\
\hline Latinur & null & C & $7+8$ & $b$ & $\omega-35, \gamma-45$ & C \\
\hline Liberdur & n.d. & & 20 & & $\omega-35, \gamma-45$ & \\
\hline Messapia & null & C & $6+8$ & $d$ & $\omega-35, \gamma-45$ & c \\
\hline Neolatino & $2 *$ & $\mathrm{~b}$ & $7+8$ & $b$ & $\omega-35, \gamma-45$ & c \\
\hline Normanno & null & C & $7+8$ & $\mathrm{~b}$ & $\omega-35, \gamma-45$ & C \\
\hline Preco & null & $\mathrm{C}$ & $6+8$ & $\mathrm{~d}$ & $\omega-35, \gamma-45$ & c \\
\hline Primadur & null & $\mathrm{C}$ & $6+8$ & $d$ & $\omega-35, \gamma-45$ & C \\
\hline Saragolla & null & $\mathrm{C}$ & $6+8$ & $d$ & $\omega-35, \gamma-45$ & C \\
\hline Svevo & null & C & $7+8$ & $b$ & $\omega-35, \gamma-45$ & c \\
\hline Tiziana & null & $\mathrm{C}$ & $7+8$ & $\mathrm{~b}$ & $\omega-35, \gamma-45$ & $\mathrm{C}$ \\
\hline
\end{tabular}

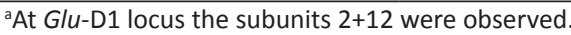

n.d. = not determined.

GPC and gluten quality of wheat are the most important factors affecting pasta consistency and resistance to overcooking ( $D^{\prime}$ Egidio et al. 1990) and bread volume (Goesaert et al. 2005). In the examined set of 29 wheat accessions and cultivars, the GPC varied in the range comprised between $14.0 \%$ and $19.5 \%$ (Table 5). As expected for wild materials, the highest values were observed in ssp. dicoccoides, and confirmed the levels ascertained in the same materials in previous researches (Taranto et al. 2012). Among the durum cultivars, Preco showed the highest value of GPC, and also the line CItr 14629 showed a considerably high level of proteins. 
Table 4. Results of the analysis of variance carried out on grain protein content (GPC), wet gluten (WG), dry gluten (DG), gluten hydration index (GHI), dry gluten/protein ratio (DG/GPC), gluten index (GI), sodium dodecyl sulphate sedimentation volume (SDS$\mathrm{SV}$ ), thousand-kernel weight (KW), and color indices ( $\mathrm{YI}=$ yellow index; $\mathrm{RI}=$ red index; $\mathrm{BI}$ = brown index) of whole meal of parental lines of wheat mapping populations grown in Valenzano (Bari, Italy) in 2013

\begin{tabular}{lllllllllllll}
\hline $\begin{array}{l}\text { Source of } \\
\text { variation }\end{array}$ & d.f. & GPC & WG & DG & GHI & DG/GPC & GI & SDS-SV & KW & YI & RI & BI \\
\hline Replication & 2 & $18.64^{* * *}$ & $442.59^{* * *}$ & $44.14^{* * *}$ & $3.35^{* *}$ & $474.11^{* * *}$ & 103.25 & $515.33^{* * *}$ & $94.30^{* *}$ & $1.79^{* *}$ & $0.54^{* * *}$ & $2.91^{* * *}$ \\
Genotype & 28 & $4.40^{* * *}$ & $267.82^{* * *}$ & $15.45^{* * *}$ & $11.07^{* * *}$ & $294.65^{* * *}$ & $2101.22^{* * *}$ & $573.54^{* * *}$ & $225.19^{* * *}$ & $13.25^{* * *}$ & $1.20^{* * *}$ & $8.78^{* * *}$ \\
Error & 55 & 0.55 & 10.88 & 0.84 & 0.55 & 22.30 & 36.72 & 31.94 & 7.93 & 0.33 & 0.05 & 0.29 \\
\hline$* * * * *$
\end{tabular}

$* *, * * *$ indicate significant differences at $p<0.01$ and $p<0.001$, respectively. The ANOVA was carried out on 29 genotypes. The accession MG4343 has not been included in the statistical analyses due to incomplete data.

The portion of total protein represented by gluten showed a high variability among the tested whole meals. Due to its strong correlation with GPC $(R=0.78, p<0.001$, and $R=0.86, p<0.001$, for WG and DG, respectively) (Table 6), gluten content paralleled the trend of proteins, with higher values in ssp. dicoccoides and in CItr 14629 than in the cultivars. High DG and WG contents were observed also in Chinese Spring and Chinese Spring - 5A dic. The lowest DG to GPC ratio was observed in cv. Saragolla, while the highest values were reached in Chinese Spring, Chinese Spring - 5A dic. and in MG5323 line.

DG varied from $8.0 \%$ (cv. Saragolla) to $15.7 \%$ (Cltr 14629), with a GHI ranging from 66.8 (cv. Aureo) to 72.8 (Chinese Spring - 5A dic.). A positive correlation was observed between DG and GHI $(R=0.64, p<0.001)$.

GI is widely used for evaluating gluten strength ( $\mathrm{Gl}<30$ = weak; 30-80 = normal; > 80 = strong) (Cubadda et al. 1992). It is known to correlate with SDS-SV, alveograph work (Cubadda et al. 1992), loaf volume (Kieffer et al. 1998), and mixograph peak time (Gaines et al. 2006). This parameter reproduces the manual gluten quality evaluation, but being instrumentally determined avoids any influence of the operator on the results. In addition, it has been reported to have high heritability (Ames et al. 1999) and, due to the relatively small-scale and rapidity of the method used for its determination, is a reliable predictor of gluten strength for screening early breeding generations (Sissons et al. 2005).

The GI of the examined wheat samples was negatively correlated with WG and DG content $(R=-0.81, p<0.001$ and $R=-0.67, p<0.001$, respectively), confirming the findings of Cubadda et al. (1992) and Peña (2000), so that higher WG and DG levels corresponded to lower gluten strength. Furthermore, a negative correlation was observed between $\mathrm{Gl}$ and $\mathrm{GHI}(R=-0.97 ; p<0.001)$, i.e. stronger the gluten, lower the hydration.

Very low GI values, indicating a very weak and sticky gluten, insufficient for both bread-making and pasta production, were observed in the dicoccum accession MG5323, in the durum line Cltr 14629, and in cv. Latino. Among the $T$. aestivum samples, Chinese Spring and its disomic substitution line Chinese Spring 5A-dic. also showed weak gluten, in agreement with their protein allelic composition. The highest values of GI $(\geq 90)$ were observed in Fiore, Neolatino, Normanno, and Saragolla durum cultivars, indicating the presence of strong gluten network with optimal pasta-making properties (Sissons et al. 2005). The very low and very high GI values observed in Latino and Neolatino, respectively, agreed with the differences observed in their protein allelic composition. An intermediate behavior was assessed in Cv. AC Avonlea, in the accession MG4330 and in the line 02-5B-318, while all the other cultivars and accessions showed GI values higher than 60 .

Besides the production of pasta, durum wheat bread-making is an established tradition in Southern Italy and in Mediterranean countries (Qaroni 1996, Pasqualone 2012). Apart the above cited few cases, characterized by extremely low GI values, the majority of the whole meals tested appeared to be able to ensure good bread-making performances. In fact, according to Curic et al. (2001), GI values between 75 and 90 provide optimal bread-making quality, while Har Gil et al. (2011) indicate that for bread-making is sufficient a value above 55 . The observed values were similar to those ascertained in a previous survey on the quality of durum wheat semolina used for bread-making in Southern Italy (Pasqualone et al. 2004).

The SDS-SV ranged from $31 \mathrm{~mL}$ to $82 \mathrm{~mL}$ and was significantly correlated with $\mathrm{GI}(R=0.65, p<0.001)$. The majority of the cultivars of both ssp. aestivum and ssp. durum showed SDS-SV values exceeding 70 , with the highest value in the breeding line 02-5B-318 for ssp. aestivum and in cv. Primadur for ssp. durum. Lower values were observed in ssp. dicoccoides and ssp. dicoccum samples, with the exception of MG29896. The SDS-SV test is based on the property of the gluten-forming endosperm storage proteins to swell and flocculate in a weak acid solution (lactic acid). 
The rate of sedimentation is influenced by gluten strength: meals containing better quality gluten show slower rates and higher SDS-SV values (Axford et al. 1979). This index is correlated with bread-making quality (Axford et al. 1979), as well as with spaghetti cooking quality (Dick and Quick 1983), hence it is widely used to evaluate flour quality in both durum and soft wheat.

Table 5. Grain protein content (GPC), wet gluten (WG), dry gluten (DG), gluten hydration index (GHI), dry gluten/protein ratio (DG/GPC), gluten index (GI), sodium dodecyl sulphate sedimentation volume (SDS-SV), thousand-kernel weight (KW), and color indices ( $\mathrm{YI}=$ yellow index; $\mathrm{RI}=$ red index; $\mathrm{BI}=$ brown index) of whole meal of parental lines of wheat mapping populations grown in Valenzano (Bari, Italy) in 2013 (mean of three field replications)

\begin{tabular}{|c|c|c|c|c|c|c|c|c|c|c|c|}
\hline Cultivar or accession & $\begin{array}{c}\text { GPC } \\
\text { (\% d.m.) }\end{array}$ & $\begin{array}{c}\text { WG } \\
\text { (\% d.m.) }\end{array}$ & $\begin{array}{c}\text { DG } \\
\text { (\% d.m.) }\end{array}$ & $\mathrm{GHI}$ & DG/GPC & $\mathrm{Gl}$ & $\begin{array}{l}\text { SDS- } \\
\text { SV } \\
(\mathrm{mL})\end{array}$ & $\begin{array}{l}K W \\
(\mathrm{~g})\end{array}$ & $\mathrm{YI}$ & $\mathrm{RI}$ & $\mathrm{BI}$ \\
\hline
\end{tabular}

\begin{tabular}{|c|c|c|c|c|c|c|c|c|c|c|c|}
\hline \multicolumn{12}{|c|}{ Triticum aestivum L. ssp. aestivum } \\
\hline Chinese Spring & 16.4 & 57.0 & 15.6 & 72.6 & 95.0 & 25 & 61 & 31.1 & 10.5 & 1.1 & 14.2 \\
\hline Chinese Spring - 5A dic. & 16.1 & 55.1 & 15.0 & 72.8 & 93.5 & 28 & 75 & 29.7 & 10.0 & 0.9 & 13.6 \\
\hline $02-5 B-318$ & 16.9 & 50.1 & 14.4 & 71.3 & 85.2 & 47 & 79 & 39.6 & 10.6 & 1.5 & \\
\hline
\end{tabular}

Triticum turgidum ssp. dicoccoides (Körn. ex Asch. \& Graebner) Thell.

\begin{tabular}{|c|c|c|c|c|c|c|c|c|c|c|c|}
\hline MG29896 & 18.8 & 50.2 & 16.1 & 67.9 & 85.5 & 75 & 68 & 48.5 & 14.9 & 1.0 & 16.2 \\
\hline MG4343 & 19.5 & n.d. & n.d. & n.d. & n.d. & n.d. & 46 & 25.3 & 12.3 & 1.8 & 19.3 \\
\hline MG4330 & 17.7 & 54.0 & 15.6 & 71.0 & 88.3 & 46 & 59 & 42.0 & 12.9 & 1.7 & 17.9 \\
\hline \multicolumn{12}{|c|}{ Triticum turgidum ssp. dicoccum (Schrank ex Schübler) Thell. } \\
\hline MG5323 & 17.8 & 55.0 & 15.5 & 71.8 & 87.3 & 19 & 36 & 37.3 & 13.6 & 2.0 & 18.7 \\
\hline \multicolumn{12}{|c|}{ Triticum turgidum ssp. durum (Desf.) Husnot } \\
\hline Cltr 14629 & 17.5 & 55.7 & 15.7 & 71.9 & 89.8 & 23 & 31 & 46.8 & 11.5 & 2.5 & 23.0 \\
\hline UC1113 & 16.3 & 39.5 & 12.9 & 67.3 & 78.9 & 87 & 64 & 50.2 & 14.1 & 0.6 & 15.2 \\
\hline Anco Marzio & 15.1 & 33.3 & 10.7 & 67.8 & 71.2 & 87 & 61 & 50.4 & 14.2 & 0.7 & 15.4 \\
\hline Aureo & 16.8 & 37.1 & 12.3 & 66.8 & 73.6 & 87 & 77 & 55.9 & 15.2 & 0.4 & 15.8 \\
\hline AC Avonlea & 16.2 & 48.4 & 14.1 & 70.9 & 87.2 & 38 & 54 & 48.7 & 16.7 & 0.0 & 15.1 \\
\hline Ciccio & 15.6 & 36.2 & 11.5 & 68.3 & 73.4 & 78 & 70 & 60.2 & 14.4 & 0.4 & 15.9 \\
\hline Duilio & 15.8 & 34.8 & 11.1 & 68.0 & 70.0 & 80 & 58 & 61.9 & 13.7 & 0.7 & 15.6 \\
\hline Fiore & 14.0 & 25.1 & 8.2 & 67.4 & 58.4 & 92 & 60 & 46.5 & 13.4 & 0.4 & 14.6 \\
\hline Grecale & 15.2 & 38.9 & 12.2 & 68.6 & 80.6 & 66 & 62 & 44.5 & 16.1 & 0.1 & 15.7 \\
\hline Iride & 14.2 & 30.0 & 9.5 & 68.3 & 66.7 & 88 & 59 & 53.8 & 14.5 & 0.5 & 15.4 \\
\hline Isildur & 14.8 & 36.3 & 11.7 & 67.7 & 78.8 & 84 & 74 & 50.4 & 17.8 & 0.0 & 16.0 \\
\hline Latino & 14.2 & 40.0 & 11.2 & 71.9 & 78.1 & 17 & 32 & 60.9 & 12.7 & 0.4 & 14.7 \\
\hline Latinur & 15.4 & 40.9 & 12.7 & 69.1 & 82.1 & 69 & 59 & 54.3 & 15.5 & 0.3 & 16.1 \\
\hline Liberdur & 14.3 & 34.7 & 11.3 & 67.5 & 78.7 & 85 & 73 & 52.3 & 17.2 & 0.2 & 15.9 \\
\hline Messapia & 16.1 & 40.9 & 12.7 & 68.8 & 79.1 & 68 & 75 & 59.2 & 12.8 & 0.8 & 15.5 \\
\hline Neolatino & 15.7 & 33.6 & 10.8 & 67.7 & 69.2 & 90 & 73 & 58.8 & 13.2 & 0.4 & 15.0 \\
\hline Normanno & 14.4 & 28.0 & 9.2 & 67.4 & 63.1 & 91 & 71 & 51.2 & 16.6 & 0.3 & 15.9 \\
\hline Preco & 17.5 & 50.1 & 15.4 & 69.2 & 88.0 & 59 & 65 & 54.3 & 16.8 & 0.1 & 16.0 \\
\hline Primadur & 15.8 & 34.3 & 11.2 & 67.2 & 70.5 & 86 & 82 & 35.0 & 17.6 & 0.1 & 15.6 \\
\hline Saragolla & 14.6 & 24.8 & 8.0 & 67.7 & 54.6 & 92 & 65 & 51.0 & 15.4 & 0.5 & 15.6 \\
\hline Svevo & 14.6 & 35.3 & 11.1 & 68.6 & 75.5 & 65 & 69 & 55.6 & 13.8 & 0.6 & 15.6 \\
\hline Tiziana & 15.0 & 37.3 & 11.8 & 68.5 & 78.0 & 76 & 66 & 52.7 & 14.5 & 0.4 & 15.1 \\
\hline
\end{tabular}

n.d. = not determined for insufficient seed

KW values ranging from $25.3 \mathrm{~g}$ to $61.9 \mathrm{~g}$ were observed, higher in durum cultivars than in the other wheats considered. Among the ssp. dicoccoides an interesting high value of KW was assessed, accounting for $48.5 \mathrm{~g}$, in MG29896. Values above $50 \mathrm{~g}$ were observed in almost all the durum cultivars, with the highest value in cv. Duilio. 
Table 6. Pearson correlation coefficients (R) among protein content (GPC), wet gluten (WG), dry gluten (DG), gluten hydration index $(\mathrm{GHI})$, dry gluten/protein ratio (DG/GPC), gluten index (GI), sodium dodecyl sulphate sedimentation volume (SDS-SV), thousandkernel weight $(\mathrm{KW})$, and color indices $(\mathrm{YI}=$ yellow index; $\mathrm{RI}=$ red index; $\mathrm{BI}=$ brown index) of parental lines of wheat mapping populations grown in Valenzano (Bari, Italy) in 2013

\begin{tabular}{|c|c|c|c|c|c|c|c|c|c|c|}
\hline & GPC & WG & DG & GHI & DG/GPC & GI & SDS-SV & KW & $\mathrm{YI}$ & RI \\
\hline WG & $0.78 * * *$ & & & & & & & & & \\
\hline DG & $0.86^{* * *}$ & $0.97 * * *$ & & & & & & & & \\
\hline GHI & 0.34 & $0.80 * * *$ & $0.64 * * *$ & & & & & & & \\
\hline G/GPC & $0.65^{* * *}$ & $0.95^{* * *}$ & $0.94 * * *$ & $0.72 * * *$ & & & & & & \\
\hline GI & $-0.39 *$ & $-0.81 * * *$ & $-0.67 * * *$ & $-0.97 * * *$ & $-0.75^{* * *}$ & & & & & \\
\hline SDS-SV & -0.09 & -0.33 & -0.21 & $-0.57^{* *}$ & -0.23 & $0.65^{* * *}$ & & & & \\
\hline KW & -0.33 & $-0.50 * *$ & $-0.44 *$ & $-0.42 *$ & $-0.43^{*}$ & 0.34 & -0.12 & & & \\
\hline YI & -0.24 & $-0.49 * *$ & -0.35 & $-0.68 * * *$ & -0.37 & $0.58 * *$ & 0.29 & 0.26 & & \\
\hline RI & $0.56 * *$ & $0.64 * * *$ & $0.56 * *$ & $0.65^{* * *}$ & $0.45^{*}$ & $-0.63 * * *$ & $-0.52^{* *}$ & -0.31 & $-0.72 * * *$ & \\
\hline $\mathrm{BI}$ & $0.44^{*}$ & $0.38^{*}$ & $0.37^{*}$ & 0.28 & 0.26 & -0.36 & $-0.56 * *$ & -0.01 & -0.09 & $0.69 * * *$ \\
\hline
\end{tabular}

Wheat kernel weight and size are important yield and quality traits, always considered primary objectives in conventional and modern wheat breeding programs. KW can be easily measured and is usually used to estimate the agronomic performance of a cultivar (Baril 1992). Moreover, it is positively correlated with high flour yield and is a cheap predictor of milling quality in bread wheat (Berman et al. 1996) and of semolina yield in durum wheat (Novaro et al. 2001).

Regarding color indices, as expected the YI (range 10.0 - 17.8) was lower in T. aestivum samples than in tetraploid wheats due to the presence, in the latter, of carotenoid pigments that are strongly correlated with yellow hue (Digesù et al. 2009). Some durum cultivars, namely Isildur, Primadur, Liberdur, Preco, and AC Avonlea, showed particularly high values of $\mathrm{Yl}$, due to the effect of breeding for this valuable characteristic. Both ssp. dicoccoides and ssp. dicoccum samples showed values in-between T. aestivum and durum cultivars.

The values of RI were generally quite low (range $0.0-2.5$ ), with the highest values in CItr14629, that is a purple wheat line characterised by high anthocyanin levels (Pasqualone et al. 2015). Although not imputable to anthocyanins, high values of RI were observed in MG5323, MG4343, and MG4330, probably originated from the oxidation of moderate levels of phenolic substances.

The highest BI, reaching the value of 23.0, was observed in Cltr14629. The origin of inherent brown color of whole meal is attributable to polyphenol oxidase activity (Taranto et al. 2012, Mangini et al. 2014), but in case of Cltr14629 the dark red color of anthocyanins probably overlapped and enhanced the brownish tone of quinone-derivatives arising from the enzymatic oxidation of phenolic compounds. Other, non-pigmented, samples also showed high $\mathrm{BI}$ values, in this case totally imputable to the oxidation of phenolics: they belonged to the ssp. dicoccoides and ssp. dicoccum, while the durum cultivars generally showed lower values. A significant correlation between $\mathrm{BI}$ and GPC was observed $(R=0.44, p<0.05)$, already reported in previous papers (Taranto et al. 2012).

\section{Selection of the crosses}

The parental lines of the crosses have to be sufficiently differentiated for the trait of interest to ensure segregation and subsequent mapping of each trait. The differences observed were markedly above $\operatorname{LSD}_{0.05}$ in many of the examined crosses (Table 7). As expected, the highest differences in GPC were observed in the crosses involving cultivars and wild accessions or landraces, namely Latino x MG29896, Latino x MG5323, Svevo x MG4330, and Messapia $\times$ MG4343, which progeny can be effectively used for mapping this character. In particular, the recombinant inbred population originated by the cross Messapia x MG4343 has already been the object of a study aimed to detect GPC-related QTLs (Blanco et al. 2002).

Similarly, the differences in DG were high in the crosses involving cultivars and wild accessions or landraces, as well as in some crosses involving cultivars, such as Neolatino $x$ Preco (Preco, in particular, was a high-gluten cultivar) and Latinur x Saragolla. The differences in WG partly resembled those in dry gluten: apart Latino x MG29896 they were marked in the crosses involving cultivars and wild accessions or landraces and, again, in the cultivar crosses Neolatino $x$ Preco and Latinur $\times$ Saragolla, but with the addition of the crosses Saragolla x 02-5B-318 (that showed the highest difference), and CItr $14629 \times$ Grecale. 
The highest DG/GPC differences were observed, in decreasing order, in Latinur x Saragolla, Isildur x Saragolla, and Liberdur $x$ Saragolla (being Saragolla a cultivar with low DG and, therefore, low DG/GPC), as well as in Grecale $x$ Fiore, Neolatino x Preco, and Duilio x AC Avonlea. Moreover, six of examined crosses showed the most differentiated values of GHI: Latino x Primadur, Svevo x MG4330, Latino x MG29896, Saragolla x 02-5B-318, Cltr 14629 x Grecale, and Duilio x AC Avonlea.

Table 7. Differences in grain protein content (GPC), wet gluten (WG), dry gluten (DG), gluten hydration index (GHI), dry gluten/protein ratio (DG/GPC), gluten index (GI), sodium dodecyl sulphate sedimentation volume (SDS-SV), thousand-kernel weight (KW), and color indices $(\mathrm{YI}=$ yellow index; $\mathrm{RI}=$ red index; $\mathrm{BI}=$ brown index) detected between parental lines of 28 wheat mapping populations

\begin{tabular}{|c|c|c|c|c|c|c|c|c|c|c|c|}
\hline Cross & $\begin{array}{l}\triangle \mathrm{GPC} \\
\text { (\% d.m.) }\end{array}$ & $\begin{array}{l}\Delta W G \\
\text { (\% d.m.) }\end{array}$ & $\begin{array}{l}\triangle D G \\
\text { (\% d.m.) }\end{array}$ & $\Delta \mathrm{GHI}$ & $\begin{array}{l}\triangle \mathrm{DG} / \\
\mathrm{GPC}\end{array}$ & $\Delta \mathrm{Gl}$ & $\begin{array}{l}\triangle S D S-S V \\
(\mathrm{~mL})\end{array}$ & $\begin{array}{l}\Delta \mathrm{KW} \\
(\mathrm{g})\end{array}$ & $\Delta \mathrm{YI}$ & $\Delta \mathrm{RI}$ & $\Delta \mathrm{BI}$ \\
\hline Aureo x Normanno & 2.4 & 9.1 & 3.1 & 0.6 & 10.5 & 4 & 6 & 4.7 & 1.4 & 0.1 & 0.1 \\
\hline Aureo $x$ Iride & 2.6 & 7.1 & 2.8 & 1.5 & 6.9 & 1 & 18 & 2.1 & 0.7 & 0.1 & 0.4 \\
\hline Neolatino x Preco & 1.8 & 16.5 & 4.6 & 1.5 & 18.8 & 31 & 8 & 4.5 & 3.6 & 0.3 & 1.0 \\
\hline Latinur $x$ Saragolla & 0.8 & 16.1 & 4.7 & 1.4 & 27.5 & 23 & 6 & 3.3 & 0.1 & 0.2 & 0.5 \\
\hline Isildur x Saragolla & 0.2 & 11.5 & 3.2 & 0.0 & 24.2 & 8 & 9 & 0.6 & 2.4 & 0.5 & 0.4 \\
\hline Liberdur x Saragolla & 0.3 & 9.9 & 3.3 & 0.2 & 24.1 & 7 & 8 & 1.3 & 1.8 & 0.3 & 0.3 \\
\hline Svevo x Primadur & 1.2 & 1.0 & 0.1 & 1.4 & 5.0 & 21 & 13 & 20.6 & 3.8 & 0.5 & 0.0 \\
\hline UC1113 x Iride & 2.1 & 9.5 & 3.4 & 1.0 & 12.2 & 1 & 5 & 3.6 & 0.4 & 0.1 & 0.2 \\
\hline Isildur x Anco Marzio & 0.3 & 3.0 & 1.0 & 0.1 & 7.6 & 3 & 13 & 0.0 & 3.6 & 0.7 & 0.6 \\
\hline Liberdur x Anco Marzio & 0.8 & 1.4 & 0.6 & 0.3 & 7.2 & 2 & 12 & 1.9 & 3.0 & 0.5 & 0.5 \\
\hline Normanno x Tiziana & 0.6 & 9.3 & 2.6 & 1.1 & 14.9 & 15 & 5 & 1.5 & 2.1 & 0.1 & 0.8 \\
\hline Svevo x Messapia & 1.5 & 5.6 & 1.6 & 0.2 & 3.6 & 3 & 6 & 3.6 & 1.0 & 0.2 & 0.1 \\
\hline $\begin{array}{l}\text { Chinese Spring } x \text { Chinese } \\
\text { Spring }-5 A \text { dic. }\end{array}$ & 0.3 & 1.9 & 0.6 & 0.2 & 1.5 & 3 & 14 & 1.4 & 0.5 & 0.2 & 0.6 \\
\hline Iride x Fiore & 0.2 & 4.9 & 1.3 & 0.9 & 8.3 & 4 & 1 & 7.3 & 1.1 & 0.1 & 0.8 \\
\hline Svevo x MG4330 & 3.1 & 18.7 & 4.5 & 4.4 & 12.8 & 19 & 10 & 13.6 & 0.9 & 1.1 & 2.3 \\
\hline Grecale x Tiziana & 0.2 & 1.6 & 0.4 & 0.1 & 2.6 & 10 & 4 & 8.2 & 1.6 & 0.3 & 0.6 \\
\hline Iride x Ciccio & 1.4 & 6.2 & 2.0 & 0.0 & 6.7 & 10 & 11 & 6.4 & 0.1 & 0.1 & 0.5 \\
\hline Normanno x Fiore & 0.4 & 2.9 & 1.0 & 0.0 & 4.7 & 1 & 11 & 4.7 & 3.2 & 0.1 & 1.3 \\
\hline Duilio x AC Avonlea & 0.4 & 13.6 & 3.0 & 2.9 & 17.2 & 42 & 4 & 13.2 & 3.0 & 0.7 & 0.5 \\
\hline CItr 14629 x Grecale & 2.3 & 16.8 & 3.5 & 3.3 & 9.2 & 43 & 31 & 2.3 & 4.6 & 2.4 & 7.3 \\
\hline Grecale $x$ Fiore & 1.2 & 13.8 & 4.0 & 1.2 & 22.2 & 26 & 2 & 2.0 & 2.7 & 0.3 & 1.1 \\
\hline Latino x MG5323 & 3.6 & 15.0 & 4.3 & 0.1 & 9.2 & 2 & 4 & 23.6 & 0.9 & 1.6 & 4.0 \\
\hline Latino x Primadur & 1.6 & 5.7 & 0.0 & 4.7 & 7.6 & 69 & 50 & 25.9 & 4.9 & 0.3 & 0.9 \\
\hline Svevo x Ciccio & 1.0 & 0.9 & 0.4 & 0.3 & 2.1 & 13 & 1 & 4.6 & 0.6 & 0.2 & 0.3 \\
\hline Saragolla x 02-5B-318 & 2.3 & 25.3 & 6.4 & 3.6 & 9.7 & 45 & 14 & 11.4 & 4.8 & 1.0 & 0.0 \\
\hline Iride x Tiziana & 0.8 & 7.3 & 2.3 & 0.2 & 11.3 & 12 & 7 & 1.1 & 0.0 & 0.1 & 0.3 \\
\hline Messapia x MG4343 & 3.4 & n.d. & n.d. & n.d. & n.d. & n.d. & 29 & 33.9 & 0.5 & 1.0 & 3.8 \\
\hline Latino x MG29896 & 4.6 & 10.2 & 4.9 & 4.0 & 7.4 & 58 & 36 & 12.4 & 2.2 & 0.6 & 1.5 \\
\hline $\mathrm{LSD}_{0.05}$ & 1.2 & 5.4 & 1.5 & 1.2 & 7.7 & 10 & 9 & 4.6 & 0.9 & 0.4 & 0.9 \\
\hline
\end{tabular}

Regarding GI, a relevant number of crosses showed marked differences. They included again Neolatino $x$ Preco and Latinur $x$ Saragolla - that could therefore be used for mapping both quantitative and qualitative features of gluten - but also many other crosses such as, in decreasing order, Latino x Primadur, Latino x MG29896, Saragolla x 025B-318, CItr 14629 x Grecale, Dulio x AC Avonlea, and Grecale x Fiore, whose corresponding recombinant inbred populations can be considered potentially useful for mapping this essential qualitative characteristic.

The differences in SDS-SV values were in accordance with those observed in GI, being these two indices correlated. In particular, the most marked differences were observed, in decreasing order, in the crosses Latino $x$ Primadur, Latino x MG29896, CItr 14629 x Grecale, and Messapia x MG4343. The recombinant inbred population originated by the latter cross has already been effectively used to detect QTLs related to SDS-SV in a previous study (Blanco et al. 1998). 
The most marked differences in KW were found in the crosses involving cultivars and wild accessions together, as well as in those involving Primadur, due to the generally low KW of this cultivar. In particular, the highest values were observed in Messapia x MG4343, Latino x Primadur, Latino x MG5323, and Svevo x Primadur.

Regarding $\mathrm{YI}$, the greatest differences between parental lines were observed for the crosses Latino $\mathrm{x}$ Primadur, Saragolla $\times 02-5 B-318$, and CItr $14629 \times$ Grecale, that appeared all suitable for mapping yellow color. As far as RI is concerned, the cross Cltr $14629 \times$ Grecale, involving a purple wheat line and a conventional non-pigmented wheat cultivar, was by far the most suitable for mapping this parameter. A weaker difference in red tone was present in some crosses, such as Latino x MG5323 and Svevo x MG4330. Not imputable to anthocyanins, this difference probably originated from the oxidation of phenolic substances occurring at different extents.

Only slight differences of BI were observed between parental lines when durum cultivars were involved, whereas more marked differences were observed in crosses involving ssp. dicoccoides or ssp. dicoccum. The highest difference was found in the cross Cltr14629 x Grecale, but probably the interference of anthocyanins could have overestimated it. Hence, although being constituted by less differentiated parental lines, the crosses Latino x MG5323, Messapia x MG4343, and Svevo x MG4330 appeared more suitable for mapping BI.

\section{Conclusions}

Overall, many of the examined crosses appeared to be suitable for studies focused on mapping each of the main quality traits of wheat (GPC, quantity and quality of gluten, KW, color indices). The derived mapping populations selected in this study are therefore all useful to investigate on these traits, because some genes are cultivar specific and need to be studied in different genetic background.

The results pointed out, also, that some populations were appropriate for studying several traits at the same time. For example, for mapping studies aimed to take into account contemporarily the quantitative and qualitative features of gluten, the populations derived from Latino x MG29896 and Saragolla x 02-5B-318 could be particularly suitable. In addition, the latter cross was the most suitable also to deepen the knowledge of YI regulation.

\section{Acknowledgement}

The authors acknowledge the financial support of MIUR in the framework of the Project PON/01_01145/8 "ISCOCEM".

\section{References}

Ames, N.P., Clarke, J.M., Marchylo, B.A., Dexter, J.E. \& Woods, S.M. 1999. Effect of environment and genotype on durum wheat gluten strength and pasta viscoelasticity. Cereal Chemistry 76: 582-586.

Axford, D.W.E., McDermott, E.E. \& Redman, D.G. 1979. Note on the sodium dodecyl sulfate test and breadmaking quality: comparison with Pelshenke and Zeleny tests. Cereal Chemistry 56: 582-584.

Baril, C.P. 1992. Factor regression for interpreting genotype-environment interaction in bread-wheat trials. Theoretical and Applied Genetics 83: 1022-1026.

Berman, M., Bason, M. L., Ellison, R., Peden, G. \& Wrigley, C.W. 1996. Image analysis of the whole grains to screen for flour-milling yield in wheat breeding. Cereal Chemistry 73: 323-327.

Bernardo, R. 2008. Molecular markers and selection for complex traits in plants: Learning from the last 20 years. Crop Science 48: 1649-1664.

Blanco, A., Bellomo, M.P., Lotti, C., Maniglio, T., Pasqualone, A., Simeone, R., Troccoli, A. \& Di Fonzo, N. 1998. Genetic mapping of sedimentation volume across environments using recombinant inbred lines of durum wheat. Plant Breeding 117: 413-417.

Blanco, A., Colasuonno, P., Gadaleta, A., Mangini, G., Schiavulli, A., Simeone, R., Digesù, A.M., De Vita, P., Mastrangelo, A.M. \& Cattivelli, L. 2011. Quantitative trait loci for yellow pigment concentration and individual carotenoid compounds in durum wheat. Journal of Cereal Science 54: 255-264.

Blanco, A., Lotti, C., Simeone, R., Signorile, A., De Santis, V., Pasqualone, A., Troccoli, A. \& Di Fonzo, N. 2001. Detection of quantitative trait loci for grain yield and yield components across environments in durum wheat. Cereal Research Communications 29: 237-244.

Blanco, A., Mangini, G., Giancaspro, A., Giove, S., Colasuonno, P., Simeone, R., Signorile, A., De Vita, P., Mastrangelo, A.M., Cattivelli, L. \& Gadaleta, A. 2012. Relationships between grain protein content and grain yield components through quantitative trait locus analyses in a recombinant inbred line population derived from two elite durum wheat cultivars. Molecular Breeding 30: 79-92.

Blanco, A., Pasqualone, A., Troccoli, A., Di Fonzo, N. \& Simeone, R. 2002. Detection of grain protein content QTLs across environments in tetraploid wheats. Plant Molecular Biology 48: 615-623.

Boggini, G. \& Pogna, N.E. 1989. The breadmaking quality and storage protein composition of Italian durum wheat. Journal of Cereal Science 9: 131-138.

Cubadda, R., Carcea, M. \& Pasqui, L.A. 1992. Suitability of the gluten index method for assessing gluten strenght in durum wheat and semolina. Cereal Foods World 37: 866-869. 
A. Pasqualone et al. (2015) 24: 118-127

Curic, D., Karlovic, D., Tusak, D., Petrovic, B. \& Dugum, J. 2001. Gluten as a standard of wheat flour quality. Food Technology and Biotechnology 39: 353-362.

D'Egidio, M.G., Mariani, B.M., Nardi, S., Novaro, P. \& Cubadda, R. 1990. Chemical and technological variables and their relationships: a predictive value equation for pasta cooking quality. Cereal Chemistry 67: 275-281.

Dick, J. \& Quick, J.S. 1983. A modified screening test for rapid estimation of gluten strength in early-generation durum wheat breeding lines. Cereal Chemistry 60: 315-318.

Digesù, A.M., Platani, C., Cattivelli, L., Mangini, G. \& Blanco, A. 2009. Genetic variability in yellow pigment components in cultivated and wild tetraploid wheats. Journal of Cereal Science 50: 210-218.

Feillet, P., Autran, J.C. \& Icard-Verniere, C. 2000. Pasta brownness: an assessment. Journal of Cereal Science 32: 215-233.

Ficco, D.B., Mastrangelo, A.M., Trono, D., Borrelli, G.M., De Vita, P., Fares, C., Beleggia, R., Platani C. \& Papa, R. 2014. The colours of durum wheat: a review. Crop and Pasture Science 65: 1-15.

Fuerst, E.P., Anderson, J.V. \& Morris, C.F. 2006. Delineating the role of polyphenol oxidase in the darkening of alkaline wheat noodles. Journal of Agricultural and Food Chemistry 54: 2378-2384.

Gadaleta, A., Giancaspro, A., Giove, S.L., Zacheo, S., Incerti, O., Simeone, R., Colasuonno, P., Nigro, D., Valé, G., Cattivelli, L., Stanca, M. \& Blanco, A. 2012. Development of a deletion and genetic linkage map for the 5A and 5B chromosomes of wheat (Triticum aestivum). Genome 55: 417-427.

Gadaleta, A. ,Giancaspro, A., Nigro, D., Giove, S. L., Incerti, O., Simeone, R., Piarulli, L., Colasuonno, P., Valè, G., Cattivelli, L. \& Blanco, A. 2014. A new genetic and deletion map of wheat chromosome $5 \mathrm{~A}$ to detect candidate genes for quantitative traits. Molecular Breeding 34: 1599-1611.

Gaines, C.S., Reid, J.F., Vander Kant, C. \& Morris, C.F. 2006. Comparison of methods for gluten strength assessment. Cereal Chemistry 83: 284-286.

Garcia-Casal, M.N. 2006. Carotenoids increase iron absorption from cereal-based food in the human. Nutrition Research 26: 340-344.

Goesaert, H., Brijs, K., Veraverbeke, W.S., Courtin, C.M., Gebruers, K. \& Delcour, J.A. 2005. Wheat flour constituents: how they impact bread quality, and how to impact their functionality. Trends in Food Science and Technology 16: 12-30.

Har Gil, D., Bonfil, D.J. \& Svoray, T. 2011. Multi scale analysis of the factors influencing wheat quality as determined by Gluten Index. Field Crops Research 123: 1-9.

ICC Standard method No. 151. 1990. Determination of the sedimentation value - SDS test of durum wheat. Wien, Austria: International Association for Cereal Science and Technology.

ICC Standard method No. 155. 1994. Determination of wet gluten quantity and quality (gluten index ac. to Perten) of whole wheat meal and wheat flour. Wien, Austria: International Association for Cereal Science and Technology.

Kieffer, R., Wieser, H., Henderson, M.H. \& Graveland, A. 1998. Correlations of the breadmaking performance of wheat flour with rheological measurements on a micro-scale. Journal of Cereal Science 27: 53-60.

Lukow, O.M., Zhang, H. \& Czarnecki, E. 1990. Milling, rheological, and end-use quality of Chinese and Canadian spring wheat cultivars. Cereal Chemistry 67: 170-176.

Mangini, G., Taranto, F., Delvecchio, L.N., Pasqualone, A. \& Blanco, A. 2014. Development and validation of a new Ppo-A1 marker useful for marker-assisted selection in tetraploid wheats. Molecular Breeding 34: 385-392.

Mather, K. \& Jinks, J.L. 1971. Biometrical Genetics. Ithaca, NY: Cornell University Press. 382 p.

McCallum, J.A. \& Walker, J.R.L. 1990. O-diphenol oxidase activity, phenolic content and colour of New Zealand wheats, flours and milling streams. Journal of Cereal Science 12: 83-96.

Novaro, P., Colucci, F., Venora, G. \& D'Egidio, M.G. 2001. Image analysis of whole grains: A non invasive method to predict semolina yield in durum wheat. Cereal Chemistry 78: 217-221.

Pasqualone, A. 2012. Italian durum wheat breads. In: Pedrosa Silva Clerici M.T. (ed.). Bread consumption and health. Hauppauge, New York, USA: Nova Publisher Inc. p. 57-80.

Pasqualone, A., Bianco, A.M., Paradiso, V.M., Summo, C., Gambacorta, G., Caponio, F. \& Blanco, A. 2015. Production and characterization of functional biscuits obtained from purple wheat. Food Chemistry 180: 64-70.

Pasqualone, A., Caponio, F. \& Simeone, R. 2004. Quality evaluation of re-milled durum wheat semolinas used for bread-making in Southern Italy. European Food Research and Technology 219: 630-634.

Pasqualone, A., Delvecchio, L.N., Mangini, G., Taranto, F. \& Blanco, A. 2014. Variability of total soluble phenolic compounds and antioxidant activity in a collection of tetraploid wheat. Agricultural and Food Science 23: 307-316.

Pasqualone, A., Summo, C., Bilancia, M.T. \& Caponio, F. 2007. Variations of the sensory profile of durum wheat Altamura PDO (Protected Designation of Origin) bread during staling. Journal of Food Science 72: S191-S196.

Peña, R.J. 2000. Durum wheat for pasta and bread-making. Comparison of methods used in breeding to determine gluten qualityrelated parameters. Options Méditerranéennes Série A: Séminaires Méditerranéennes 40: 423-430.

Piarulli, L., Gadaleta, A., Mangini, G., Signorile, M.A., Pasquini, M., Blanco, A. \& Simeone, R. 2012. Molecular identification of a new powdery mildew resistance gene on chromosome 2BS from Triticum turgidum ssp. dicoccum. Plant Science 196: 101-106.

Pogna, N.E., Autran, J.C., Mellini, F., Lafiandra, D. \& Feillet, P. 1990. Chromosome 1B-encoded gliadins and glutenin subunits in durum wheat: genetics and relationship to gluten strength. Journal of Cereal Science 11: 15-34.

Qaroni, J. 1996. Flat Bread Technology. New York, NY: Chapman \& Hall. 206 p.

Shewry, P.R., Halford, N.G. \& Tatham, A.S. 1992. High molecular weight subunits of wheat glutenin. Journal of Cereal Science 15: 105-120.

Sissons, M.J., Ames, N.P., Hare, J.A. \& Clarke, J.M. 2005. Relationship between glutenin subunit composition and gluten strength measurements in durum wheat. Journal of the Science of Food and Agriculture 85: 2445-2452.

Taranto, F., Delvecchio, L.N., Mangini, G., Del Faro, L., Blanco, A. \& Pasqualone, A. 2012. Molecular and physic-chemical evaluation of enzymatic browning of whole meal and dough in a collection of tetraploid wheats. Journal of Cereal Science 55: 405-414. 